\title{
Inhibition of cholinergic muscarinic signaling by ethanol: Potential mechanism of developmental neurotoxicity and biological plausibility for the beneficial effects of choline supplementation
}

\author{
Lucio G. Costa ${ }^{1,2}$, Gennaro Giordano ${ }^{1}$, and Marina Guizzetti ${ }^{3}$ \\ ${ }^{1}$ Department of Environmental and Occupational Health Sciences, University of Washington, Seattle, WA, United States \\ ${ }^{2}$ Department of Neuroscience, University of Parma Medical School, Parma, Italy \\ ${ }^{3}$ Jesse Brown VA Medical Center and Department of Psychiatry, University of Illinois at Chicago, Chicago, IL, United States
}

\begin{abstract}
Central nervous system dysfunctions are among the most significant effects of in utero exposure to ethanol. Ethanol has been shown to affect neurons and glial cells, causing cell loss and impaired cell migration and maturation. Multiple mechanisms have been suggested to underlie the effects of ethanol, including interference with growth factors, cytokines, cell adhesion molecules and neurotransmitters. Here, we propose that a relevant mechanism of ethanol's developmental neurotoxicity may be its ability to inhibit the actions of acetylcholine in the developing nervous system mediated by activation of cholinergic muscarinic receptors. Acetylcholine has been shown to induce proliferation of astrocytes, to protect neurons against apoptotic cell death, and to foster astrocyte-neuronal interactions, thereby increasing neuritogenesis. By interfering with muscarinic receptor signal transduction pathways (mostly at the level of phospholipase D), ethanol inhibits all these effects of acetylcholine in the developing brain. Such action of ethanol may be responsible, at least in part, for some manifestations of developmental neurotoxicity, such as microencephaly, neuronal cell death and impaired neuronal differentiation. Among potential therapeutic interventions for fetal alcohol spectrum disorders, choline supplementation appears to be one of the most promising. The cholinergic hypothesis of ethanol's developmental neurotoxicity provides biological plausibility for the beneficial effects of choline. Indeed, by "potentiating” the cholinergic system during development (through increased synthesis of acetylcholine and phosphatidylcholine, and increased phospholipase D activity), choline would antagonize at least some of the deleterious effects of ethanol.
\end{abstract}

In utero exposure to ethanol can cause fetal alcohol spectrum disorders (FASD), whose most severe manifestation is fetal alcohol syndrome (FAS), characterized by growth retardation, facial dysmorphology, and neurodevelopmental abnormalities leading to longlasting cognitive and behavioral deficits (Jones, 2011; Riley, Infante, \& Warren, 2011; Streissguth, LandesmanDwyer, Martin, \& Smith, 1980). Animal studies and human observations indicate that exposure to ethanol during the brain growth spurt causes microencephaly, which is present in more than $80 \%$ of FAS children (Samson, 1986). A large number of studies have also shown that alcohol abuse during pregnancy causes loss of certain neurons (Cui, Terwai, Schneider, \& Rubin, 1997; Ikonomidou et al., 2000), alterations in the elongation of axons and neurites (Miller, 1997; Miller, Astley, \& Clarren 1999), and modifications of glial cells, in particular astrocytes (Costa, Yagle, Vitalone, \& Guizzetti, 2004; Guerri, Pascual, \& Renau-Piqueras, 2001; Miller \& Robertson, 2003; Riley et al., 1995). For the past several years our laboratory has been pursuing the hypothesis that the signal transduction pathways activated by the neurotransmitter acetylcholine may represent a relevant target for the developmental neurotoxicity of ethanol. This review will briefly summarize the investigations carried out over the years to address this hypothesis, from the initial serendipitous observations to the mechanism-driven studies which have also uncovered novel actions of acetylcholine in the developing nervous system.

\section{The cholinergic system and brain development}

There is substantial evidence that acetylcholine may influence various aspects of brain development (AbreuVillaca, Filgueiras, \& Manhaes, 2011; Buznikov, 1984; Costa, 1993, 1996, 1998; Costa \& Guizzetti, 1999; Lauder \& Schambra, 1999; Weiss, Maness, \& Lauder, 1998). Acetylcholine is believed to have non-transmitter effects during development, as it can regulate morphogenic cell movements during gastrulation, glial cell proliferation, and neuronal differentiation and survival (Lauder \& Schambra, 1999; Lipton \& Kater, 1989; Nguyen et al., 2001).

Correspondence: Lucio G. Costa, Department. of Environmental and Occupational Health Sciences, University of Washington, 4225 Roosevelt Way NE, Suite 100, Seattle, WA, United States, 98105. Telephone: 206-543-2831. Fax: 206-685-4696. E-mail: lgcosta@u.washington.edu

Financial support: Research by the author has been supported by grants AA-08154 and P30ES07033. 
Developing neurons may fire action potentials and trigger acetylcholine secretion from the axonal growth cone while the axon is still growing, and neuron-released acetylcholine may contribute to further axonal growth and formation of synaptic contacts (Yao, Rusch, Poo, \& Wu, 2000). Furthermore, astrocytes may themselves release acetylcholine, which may act in an autocrine fashion (Wessler et al., 1997). Components of the cholinergic system, such as choline acetyltransferase and acetylcholine receptors, are present early in development, long before the appearance of synapses, and increase slowly with age (Costa, 1993; Balduini, Murphy, \& Costa, 1987; Ladinsky, Consolo, Peri, \& Garattini, 1972). Levels of choline, the rate-limiting factor in the synthesis of acetylcholine, are high in the neonatal rat brain (Ladinsky et al., 1972); this fact, together with the low activity of acetylcholinesterase, may explain why acetylcholine levels are high (80-90\% of adult values) early postnatally (Coyle \& Yamamura, 1976).

There are five distinct subtypes of muscarinic receptors, M1-M5; while the M2 and M4 subtypes are negatively coupled to adenylate cyclase, the other subtypes stimulate phospholipid hydrolysis (Hosey, 1992). In an earlier study we found that, unlike other neurotransmitter receptor systems, muscarinic receptor-stimulated phosphoinositide metabolism was much higher in brains from neonatal rats than in adult rats, despite a lower expression of muscarinic receptors (Balduini et al., 1987; Heacock, Fisher, \& Agranoff, 1987). Muscarinic receptor density increases postnatally, reaching a plateau at about four weeks of age (Balduini et al., 1987). Phosphatidylcholine hydrolysis, due to phospholipase D (PLD) activation, is also enhanced in the neonatal rat brain (Costa, Balduini, \& Reno, 1995; Zhao, Berse, Holler, Cermak, \& Blusztajn, 1998). Though the exact molecular mechanism(s) of such enhanced muscarinic receptor stimulation of phospholipid metabolism are still not fully understood, similar effects are also present in brains from neonatal mice and human fetuses (Larocca, Rodriguez-Gain, Rashbaum, Weidenheim, \& Lyman, 1994; Tan \& Costa, 1995). These initial serendipitous findings, and the fact that muscarinic receptor formation precedes the development of presynaptic markers, suggested that muscarinic receptors may play a role in the regulation of neurocytomorphogenesis, neuritogenesis, synaptogenesis and glial cell proliferation (Costa, 1993, 1996, 1998). These considerations led to our initial hypothesis that the muscarinic receptor signal transduction system may represent a possible target for the developmental neurotoxicity of ethanol.

\section{Ethanol, muscarinic receptors signal transduction and microencephaly}

Initial in vivo studies showed that administration of ethanol from postnatal days (PND) 4-10, i.e., during the brain growth spurt (Dobbing \& Sands, 1979), caused microencephaly and inhibited muscarinic receptorstimulated phosphoinositide metabolism in cerebral cortex and hippocampus (Balduini \& Costa, 1989). This exposure to ethanol did not alter the expression of muscarinic receptors (Balduini \& Costa, 1989). Thus, an early and short-lasting effect of ethanol on muscarinic signaling was associated with modification of the nervous system (microencephaly), which is a long-lasting event. Further studies investigating the dose-and time-dependence of these effects showed that microencephaly and reduced phosphoinositide metabolism were only observed when ethanol was given on PND 6-8 or 8-10, but not earlier or later, despite similar blood ethanol concentrations (BAC; $\sim 50 \mathrm{mM}$ ) (Balduini, Reno, Costa, \& Cattabeni, 1994). Furthermore, only doses capable of inhibiting phosphoinositide hydrolysis would cause microencephaly (Reno, Tan, Balduini, \& Costa, 1994). Additional studies carried out in vitro in rat brain slices showed that the sensitivity of muscarinic receptor-stimulated phosphoinositide hydrolysis to ethanol inhibition was maximal at PND 7-10; that it was more pronounced in cortex and hippocampus; that it was relatively specific for acetylcholine and muscarinic receptors compared to other neurotransmitters (e.g., norepinephrine, 5hydroxytryptamine); and that it was due to ethanol itself, rather than to its conversion to acetaldehyde (Balduini, Candura, Manzo, Cattabeni, \& Costa, 1991; Balduini \& Costa, 1990; Tan, Castoldi, Manzo, \& Costa, 1993). All together, these studies provided strong evidence of an association between the ability of ethanol to cause developmental neurotoxicity (microencephaly) and inhibition of muscarinic receptor signal transduction. However, a more meaningful causal relationship had yet to be shown.

\section{Ethanol inhibits the mitogenic action of acetylcholine in glial cells}

Prompted by an important paper by Ashkenazi, Ramachandran, and Capon (1989), we developed the hypothesis that acetylcholine may act as a mitogen in glial cells. This effect may indeed be relevant in terms of brain development, as proliferation of astrocytes is a major event occurring during the bran growth spurt, a period when muscarinic signaling is particularly enhanced (Balduini et al., 1987; Costa et al., 1995). Ethanol, by interfering with muscarinic receptor signaling, would inhibit the mitogenic action of acetylcholine in glial cells, and this would explain, at least in part, microencephaly seen upon ethanol exposure during the brain growth spurt (Balduini \& Costa, 1989; Samson, 1986). Though ethanol-induced apoptotic cell death of neurons (Ikonomidou et al., 2000) would also contribute to a reduction in brain size, the very high glia/neuron ratio suggested that a decrease in astrocyte proliferation, leading to a reduced number of astrocytes, would play a most relevant role in ethanol-induced microencephaly (Costa \& Guizzetti, 1999).

Initial experiments indicated that activation of M3 muscarinic receptors on astroglial cells (primary rat and human astrocytes, and a human astrocytoma cell line) increased DNA synthesis, and that ethanol (25-75 mM) inhibited this effect (Guizzetti \& Costa, 1996; Guizzetti, Costa, Peters, \& Costa, 1996; Guizzetti, Moeller, \& Costa, 2003) (Table 1). Further studies were aimed at investigating the signaling pathway(s) involved in the mitogenic action of acetylcholine in astroglial cells, and at identifying the molecular target(s) of ethanol's antiproliferative action. Three major signaling pathways activated by M3 muscarinic receptors were found to be 
involved in astroglial cell proliferation. A first pathway involves activation of phospholipase $\mathrm{C}$, with a subsequent increase in intracellular calcium levels, and activation of novel PKC $\varepsilon$ and of mitogen activated protein kinase (MAPK). This pathway appears to play a (minor) role in the mitogenic action of acetylcholine, and is affected only by relatively high $(>100 \mathrm{mM})$ concentrations of ethanol (Catlin, Guizzetti, \& Costa, 2000; Guizzetti \& Costa, 2000a; Yagle, Lu, Guizzetti, Moeller, \& Costa, 2001). A second pathway involves the sequential activation of PLD, formation of phosphatidic acid, activation of atypical PKC $\xi$, and activation of p70S6 kinase and of Nf-kB. Ethanol was found to target this pathway, by specifically inhibiting PLD (and, as a consequence, all downstream events) at concentrations of 25-50 mM (Guizzetti \& Costa, 2000b, 2002; Guizzetti, Bordi et al., 2003; Guizzetti, Thompson, Kim, VanDeMark, \& Costa, 2004). Similar findings were also obtained following in vivo administration of ethanol (Tsuji, Fattori, Abe, Costa, \& Kobayashi, 2008; Tsuji, Guizzetti, \& Costa, 2003). Table 2 shows the effects of in vivo ethanol administration (PND 4-7) on brain weight and levels of phospho-p70S6 kinase. A third pathway involves activation of phosphoinositide-3 kinase and subsequent activation of PKC $\xi$; this pathway was inhibited only by high concentrations of ethanol (Guizzetti \& Costa, 2001, 2002). Inhibition of astrocyte proliferation by ethanol is consistent with the reduced number of glial cells found following in vivo ethanol exposure (Miller \& Potempa, 1990; Perez-Torrero et al., 1997; Riley et al., 1995), and may contribute to ethanol-induced microencephaly (Samson, 1986). It should also be noted that activation of muscarinic receptors increases DNA synthesis in oligodendrocytes and in progenitor cells, whose proliferation may be affected by ethanol (Costa et al., 2001; Crews et al., 2003).

\section{Ethanol impairs the trophic action of acetylcholine}

Acetylcholine has also been shown to have a trophic effect in neurons by activating muscarinic receptors. Cerebellar granule cells maintained in nondepolarizing conditions undergo apoptosis, and this is antagonized by activation of muscarinic receptors (Yan, Lin, Irwin, \& Paul, 1995).
Ethanol has been shown to antagonize the anti-apoptotic action of acetylcholine in cerebellar granule neurons (Castoldi, Barni, Randine, Costa, \& Manzo, 1998). Given that activation of muscarinic M3 receptors in cerebellar neurons and in other cells antagonizes apoptosis induced by a variety of stimuli (Giordano et al., 2009), inhibition of such action by ethanol during brain development may contribute to enhanced neuronal apoptosis, which is also elicited by inhibition of other trophic signals (Castoldi et al., 1998; Ikonomidou et al., 2000). The latter, particularly those mediated by activation of the NMDA (N-methyl Daspartate) receptors, may be the most relevant (Ikonomidou et al., 2000).

\section{Ethanol inhibits astrocyte-neuron interactions involved in neuritogenesis}

Astrocytes are known to exert a profound effect on neuronal development, as they provide trophic support essential for neuronal survival and are involved in neuronal migration, axon and dendritic outgrowth, and synaptogenesis (Barres, 2008; Seth \& Koul, 2008; Ullian, Christopherson, \& Barres, 2004; Volterra \& Meldolesi, 2005). Astrocytes express and release molecules that promote (e.g., fibronectin) or inhibit (e.g., neurocan) neurite outgrowth, thus playing an important role during brain development and regeneration after lesions (Pagani et al., 1991; Rauch, Feng, \& Zhou, 2001). We hypothesized that activation of muscarinic receptors in astrocytes may increase the expression and release of permissive factors leading to neuronal differentiation, most notably neuritogenesis, and that by inhibiting muscarinic receptor signal transduction, ethanol would inhibit these effects. Rat cortical or hippocampal astrocytes incubated with carbachol and then co-cultured for 24 hours with rat hippocampal neurons stimulated neuritogenesis, as assessed morphologically (Guizzetti, Moore, Giordano, \& Costa, 2008); length of the longest neurite (identified as the axon by Tau- 1 staining) was increased by $2-3$-fold, while length of minor neurites (identified by MAP-2 staining) and number of neurites per cell were increased by 2-fold.

The effect of carbachol was due to the activation of M3 muscarinic receptors in astrocytes, was not related to an increased number of astrocytes (as, under these

Table 1

Effect of ethanol on carbachol-induced proliferation of astroglial cells

\begin{tabular}{|c|c|c|c|c|c|}
\hline Cell Type & $\begin{array}{c}\text { Carbachol } \\
(1 \mathrm{mM})\end{array}$ & \multicolumn{4}{|c|}{ Ethanol (mM) } \\
\hline Rat cortical astrocytes & 100 & 50 & 30 & 18 & 3 \\
\hline Human fetal astrocytes & 100 & 70 & 45 & 10 & nd \\
\hline 1321N1 human astrocytoma & 100 & 40 & 25 & 18 & 2 \\
\hline
\end{tabular}

Note. Proliferation of astroglial cells was measured by ${ }^{3} \mathrm{H}$-thymidine incorporation into DNA. Cells were treated for $24 \mathrm{~h}$ with 1 mM carbachol in the absence or presence of ethanol. Results are expressed as percentage of carbachol's effects. All data with ethanol are significantly different from carbachol. Stimulation of proliferation by carbachol (1 mM) ranged from 3- to 9-fold, depending on cell type. No cytotoxicity was observed in any experimental condition. Data are adapted from Guizzetti \& Costa (1996) and Guizzetti, Bordi et al. (2003a). 
Table 2

Effect of ethanol on brain weight and phospho-p70S6 kinase

\begin{tabular}{lcccc}
\hline & & \multicolumn{3}{c}{ Ethanol (mg/kg) } \\
\cline { 3 - 5 } End Point & Control & $\mathbf{2}$ & $\mathbf{4}$ & $\mathbf{6}$ \\
\hline Body weight (g) & 16.4 & 16.9 & 16.2 & $12.9^{*}$ \\
Brain weight (mg) & 741.0 & 756.0 & $706.0^{*}$ & $627.0^{*}$ \\
BAC (mM) & - & 25.0 & 64.0 & 92.0 \\
Phosho p70S6K (\%) & 100.0 & $50.0^{*}$ & $20.0^{*}$ & $5.0^{*}$ \\
\hline
\end{tabular}

Note. Male rats were given ethanol or an equicaloric sucrose solution by gavage from PND 4 to 7 and were sacrificed 45 min after the last treatment. *Significantly different from control, $p<0.05$. Data are adapted from Tsuji et al. (2003).

Table 3

Effect of ethanol on astrocyte-mediated neuritogenesis

\begin{tabular}{lcrrr}
\hline & & \multicolumn{3}{c}{ Ethanol (mM) } \\
\cline { 3 - 5 } End Point & Control & $\mathbf{2 5}$ & $\mathbf{5 0}$ & $\mathbf{1 0 0}$ \\
\hline Average length of longest neurite (um) & 58.0 & 57.0 & 53.0 & 53.0 \\
Average length of minor neurites (um) & 22.0 & 21.0 & 22.0 & 20.0 \\
Number of neurites/cell & 3.8 & 3.7 & 3.7 & 3.8 \\
& + Carbachol & & & \\
Average length of longest neurite (um) & 160.0 & $140.0^{*}$ & $70.0^{*}$ & $60.0^{*}$ \\
Average length of minor neurites (um) & 42.0 & 40.0 & $27.0^{*}$ & $24.0^{*}$ \\
Number of neurites/cell & 8.0 & $7.1^{*}$ & $4.5^{*}$ & $4.0^{*}$ \\
\hline
\end{tabular}

Note. Rat cortical astrocytes were exposed for $24 \mathrm{~h}$ to ethanol $(25,50$ or $100 \mathrm{mM})$ in the absence (control) or the presence of $1 \mathrm{mM}$ carbachol. After wash-out, astrocytes were co-cultured with rat hippocampal neurons for an additional $24 \mathrm{~h}$. Neurons were then stained with $\beta I I I-t u b u l i n$ antibody for morphometric analysis. *Significantly different from carbachol alone, $p<0.05$. Data are adapted from Guizzetti et al. (2010).

experimental conditions, carbachol did not stimulate DNA synthesis (Guizzetti, Wei, \& Costa, 1998)), and was mediated by multiple signaling pathways in astrocytes, including the PLD, PKC $\xi$, p70S6 kinase and NF-kB pathway, the PI-3K, PKC $\xi$, p70S6 kinase pathway, and the PKC̣ \&, MAPK pathway (Guizzetti, Moore, VanDeMark, Giordano, \& Costa, 2011). When astrocytes were incubated with carbachol in the presence of various concentrations of ethanol (25, 50, $75 \mathrm{mM})$, and then cocultured with neurons, neuritogenesis was significantly inhibited (Table 3) (Guizzetti, Moore, Giordano, VanDeMark, \& Costa, 2010). The effect of ethanol was due to inhibition of PLD, as it was mimicked by 1-butanol (a PLD inhibitor), but not by tert-butanol, an analog that does not undergo the transphosphatidylation reaction, and thus does not affect PLD activity (Guizzetti et al., 2010).

Conditioned medium from primary rat astrocytes was analyzed by shotgun proteomics, and 302 different proteins were identified by gene ontology analysis; of these, 133 (43\%) were secreted (extracellular) proteins, most of which were involved in neuronal development (Moore, Costa, Shaffer, Goodlett, \& Guizzetti, 2009). Exposure of astrocytes to carbachol increased the expression of the extracellular matrix (ECM) proteins fibronectin and laminin in these cells and in the medium; this was due in part to an increase in laminin and fibronectin mRNA levels, and in part to the up-regulation of plasminogen activator inhibitor-1 (PAI-1), an inhibitor of the proteolytic degradation of the ECM, which has neuritogenic properties on its own. The effects of carbachol on ECM proteins were due to activation of muscarinic M3 receptors, and were mediated by the same signaling pathways in astrocytes shown to be involved in carbachol-stimulated, astrocytemediated neurite outgrowth (Guizzetti et al., 2011). Inhibition of fibronectin activity (with a function-blocking antibody) strongly reduced the effect of carbachol on the elongation of all the neurites, while inhibition of laminin activity reduced the elongation of minor neurites only (Guizzetti et al., 2008). Ethanol (25-50 mM) decreased the levels of ECM proteins and of PAI-1 in astrocytes; this effect was also due to inhibition of PLD, as substantiated by the fact that phosphatidic acid, a product of phosphatidylcholine hydrolysis by PLD, increased fibronectin and laminin expression in astrocytes, and that these effects were not altered by ethanol (Guizzetti et al., 2010).

The direct effect of carbachol on hippocampal pyramidal neurons was also investigated. By activating M1, rather than M3, muscarinic receptors, carbachol increased the length of the longest neurite, but did not alter minor neurite length. This effect involved primarily activation of Erk 1,2 
MAPK (VanDeMark, Guizzetti, Giordano, \& Costa, 2009a). Ethanol inhibited the direct neuritogenic effect of carbachol by inhibiting MAPK activation, but only at concentrations of $50 \mathrm{mM}$ or higher (VanDeMark, Guizzetti, Giordano, \& Costa, 2009b).

To more closely mimic an in vivo situation, the effects of carbachol and of ethanol on neuritogenesis of hippocampal neurons were also investigated in a more complex system: the hippocampal slice in culture (Giordano, Guizzetti, Dao, Mattison, \& Costa, 2011). Exposure of hippocampal slices to carbachol (1 mM for $24 \mathrm{~h}$ ) induces neurite outgrowth in hippocampal pyramidal neurons (a 4.7-fold increase in the length of the longest neurite, a 3.7-fold increase in minor neurite length, and a 3.2-fold increase in the number of branches), while the number of neurites per cell is unchanged (Giordano et al., 2011). Ethanol (50 mM) inhibits all effects induced by carbachol. In agreement with earlier findings in astrocyte-neuron co-cultures, carbachol increases the levels of fibronectin and laminin, and these are inhibited by ethanol. The effects of carbachol on neurite outgrowth and ECM protein levels were both mediated by M3 receptors, suggesting that its neuritogenic effect is indirect, primarily due to activation of muscarinic receptors on astrocytes. Furthermore, fibronectin and laminin function-blocking antibodies antagonized the neuritogenic effect of carbachol, indicating again that it was due to a primary action on astrocytes (Giordano et al., 2011).

All together, these findings are supportive of previous observations of an effect of ethanol on neuronal differentiation upon in vivo exposure (Davies \& Smith, 1981; Smith \& Davies, 1990), and may explain contrasting results previously obtained in vitro in neurons (Bearer, Swick, O’Riordan, \& Cheng, 1999; Zou, Rabin, \& Pentney, 1993). Indeed, the primary effect of ethanol is due to inhibition of muscarinic receptor signaling in astrocytes, which in turn affects astrocyte-neuron cross-talks.

\section{Choline supplementation and ethanol's developmental neurotoxicity}

The studies summarized above have identified novel actions of acetylcholine in the developing nervous system, due to activation of muscarinic receptors, particularly in astrocytes, and have shown that by inhibiting muscarinic receptor signal transduction, ethanol antagonizes such developmental effects of acetylcholine. We believe that these mechanistic findings may provide biological plausibility for mechanism-driven therapeutic interventions, particularly for the use of choline.

During the past several years, a series of studies have provided ample evidence that choline supplementation (either prenatally or postnatally) attenuates several behavioral effects associated with prenatal or neonatal ethanol exposure. In an initial study, choline, given postnatally, was shown to ameliorate the effects of prenatal ethanol exposure on a discrimination learning task (Thomas, La Fiette, Quinn, \& Riley, 2000). Similar results were also found in studies in which both choline and ethanol (under different paradigms) were given post-natally
(Ryan, Williams, \& Thomas, 2008; Thomas, Biane, O’Bryan, O’Neill, \& Dominguez, 2007; Thomas, Garrison, \& O’Neill, 2004). Choline also prevented ethanol-induced deficits in trace fear conditioning (Wagner \& Hunt, 2006), but did not mitigate motor coordination deficits (Thomas, O’Neill, \& Dominguez, 2004). Prenatal administration of choline also prevented effects of prenatal ethanol on brain weight, working memory tests, and most developmental behavioral measures (Thomas, Abou, \& Dominguez, 2009; Thomas, Idrus, Monk, \& Dominguez, 2010). The beneficial effects of choline are not due to alterations of ethanol's pharmacokinetics, as BAC is not changed by choline. Hypotheses formulated to explain the effects of choline are basically of two types (Thomas, Monk, Idrus, Otero, \& Kelly, 2011): (1) choline, which contains three methyl groups, may influence DNA methylation, thus acting through epigenetic mechanisms, or may affect methylation of homocysteine to methionine (Hobbs, Cleves, Melnyk, Zhao, \& James, 2005; Zeisel, 2011); and (2) choline may affect the developing cholinergic system. The latter hypothesis would be in concordance with the cholinergic hypothesis previously indicated. Choline is a precursor of the neurotransmitter acetylcholine, of the membrane phospholipid phosphatidylcholine (the substrate of PLD), as well as of sphyngomyelin, and of lysophosphatidylcholine (Wurtman, Cansev, Sakamoto, \& Ulus, 2009). Additionally, choline may act as a direct agonist at nicotinic and muscarinic receptors (Costa, Kaylor, \& Murphy, 1986; Costa \& Murphy, 1984). Free choline readily passes the blood-brain barrier (Cornford, Braun, \& Oldendorf, 1978), and in vivo pre- or post-natal choline administration has been shown to decrease acetylcholinesterase activity (which would lead to an increase in acetylcholine) (Cermak et al., 1999; Cermak, Holler, Jackson, \& Blusztajn, 1998); increase PLD activity (Holler, Cermak, \& Blusztajn, 1996); increase potassiumevoked release of acetylcholine in the hippocampus (Cermak et al., 1998; Napoli, Blusztajn, \& Mellott, 2008); increase hippocampal responsiveness to carbachol (Montoya et al., 2000); and increase basal dendritic arborization in hippocampal CA1 pyramidal neurons ( $\mathrm{Li}$ et al., 2004). Animal studies have shown that prenatal ethanol exposure decreases phosphatidylcholine levels in the hippocampus (Wen \& Kim, 2004). In humans, a magnetic resonance spectroscopy study has found decreased levels of choline in some brain regions of 12-year-old children diagnosed with FAS (Astley et al., 2009). Using the same approach, it has been shown that choline administration to humans increases the level of choline and its metabolites (e.g. phosphocholine) in the brain (Babb et al., 2004).

\section{Conclusion}

Developmental exposure to ethanol alters cholinergic muscarinic receptor signaling, particularly in the hippocampus, a brain region which is believed to mediate many of the effects seen after ethanol exposure (Berman \& Hannigan, 2000). While abstaining from alcohol consumption is obviously the best preventive measure for FASD and FAS, it is recognized that therapeutic approaches would be valuable. In this regard, studies 
showing the beneficial effects of choline appear the most promising (Jones, 2011; Thomas et al., 2010). The observations that choline, which is easily available and safe, can ameliorate some developmental neurotoxic effects of ethanol, in particular hippocampus-mediated behaviors, make this compound an ideal candidate for such endeavors. The mechanisms underlying the beneficial action of choline in animal models have not been determined; however, several studies have shown that a primary target for choline is the cholinergic system in the hippocampus, which is also targeted by ethanol. The main biological substrates of choline's action in the nervous system are related to the cholinergic system (e.g. acetylcholine, phosphatidylcholine, PLD). The hypothesis that choline supplementation would antagonize ethanol's developmental neurotoxicity by "potentiating" cholinergic actions in the developing nervous system appears to warrant further investigation. Also of interest, from a practical clinical viewpoint, is the finding that choline appears to conserve its efficacy even if given after ethanol administration (Thomas et al., 2000), which would be of much relevance in the continuous quest for therapeutic interventions for FAS/FASD.

\section{Acknowledgments}

The authors thank all collaborators who have contributed to their studies over the years and NIAAA for research support.

\section{References}

Abreu-Villaca, Y., Filgueiras, C. C., \& Manhaes, A. C. (2011). Developmental aspects of the cholinergic system. Behavioral Brain Research, 221, 367-378.

Ashkenazi, A., Ramachandran, J., \& Capon, D. J. (1989). Acetylcholine analogue stimulates DNA synthesis in brain-derived cells via specific muscarinic receptor subtypes. Nature, 340, 146-150.

Astley, S. J., Richards, T., Aylward, E. H., Olson, H. C., Kerns, K., Brooks, A., . . . Maravilla, K. (2009). Magnetic resonance spectroscopy outcomes from a comprehensive magnetic resonance study of children with fetal alcohol spectrum disorders. Magnetic Resonance Imaging, 27, 760-778.

Babb, S. M., Ke, Y., Lange, N., Kaufman, M. J., Renshaw, P. F., \& Cohen, B. M. (2004). Oral choline increases choline metabolites in human brain. Psychiatry Research: Neuroimaging, 130, 1-9.

Balduini, W., Candura, S. M., Manzo, L., Cattabeni, F., \& Costa, L. G. (1991). Time-, concentration-, and agedependent inhibition of muscarinic receptor-stimulated phosphoinositide metabolism by ethanol in the developing rat brain. Neurochemical Research, 16, 1235-1240.

Balduini, W., \& Costa, L. G. (1989). Effects of ethanol on muscarinic receptor-stimulated phosphoiositide metabolism during brain development. The Journal of Pharmacology and Experimental Therapeutics, 250, 541-547.
Balduini, W., \& Costa, L. G. (1990). Developmental neurotoxicity of ethanol: In vitro inhibition of muscarinic receptor-stimulated phosphoinositide metabolism in brain from neonatal but not adult rats. Brain Research, 512, 248-252.

Balduini, W., Murphy, S. D., \& Costa, L. G. (1987). Developmental changes in muscarinic receptorstimulated phosphoinositide metabolism in rat brain. The Journal Pharmacology and Experimental Therapeutics, 241, 421-427.

Balduini, W., Reno, F., Costa, L. G., \& Cattabeni, F. (1994). Developmental neurotoxicity of ethanol: Further evidence for an involvement of muscarinic receptor-stimulated phosphoinositide metabolism. European Journal of Pharmacology: Molecular Pharmacolology, 266, 283-289.

Barres, B. A. (2008). The mystery and magic of glia: A perspective on their roles in health and disease. Neuron, 60, 430-440.

Bearer, C. F., Swick, A. R., O’Riordan, M. A., \& Cheng, G. (1999). Ethanol inhibits L1-mediated neurite outgrowth in postnatal rat cerebellar granule cells. Journal of Biological Chemistry, 274, 13264-13270.

Berman, R. F., \& Hannigan, J. H. (2000). Effects of prenatal alcohol exposure on the hippocampus: Spatial behavior, electrophysiology, and neuroanatomy. Hippocampus, 10, 94-110.

Buznikov, G. A. (1984). The action of neurotransmitters and related substances on early embryogenesis. Journal of Clinical Pharmacology, Therapy and Toxiology, 25, 23-59.

Castoldi, A. F., Barni, S., Randine, G., Costa, L. G., \& Manzo, L. (1998). Ethanol selectively interferes with the trophic action of NMDA and carbachol on cultured cerebellar granule cells undergoing apoptosis. Developmental Brain Research, 111, 279-289.

Catlin, M. C., Guizzzetti, M., \& Costa, L. G. (2000). Effect of ethanol on muscarinic receptor-induced calcium responses in astroglia. Journal of Neuroscience Research, 60, 345-355.

Cermak, J. M., Blusztajn, J. K., Meck, W. H., Williams, C. L., Fitzgerald, C. M., Rosene, D. L., \& Loy, R. (1999). Prenatal availability of choline alters the development of acetylcholinesterase in the rat hippocampus. Developmental Neuroscience, 21, 94-104.

Cermak, J. M., Holler, T., Jackson, D. A., \& Blusztajn, J. K. (1998). Prenatal availability of choline modifies development of the hippocampal cholinergic system. The FASEB Journal, 12, 349-357.

Cornford, E. M., Braun, L. D., \& Oldendorf, W. H. (1978). Carrier mediated blood-brain barrier transport of choline and ceratin choline analogs. Journal of Neurochemistry, 30, 299-308.

Costa, L. G. (1993). Muscarinic receptors in the developing nervous system. In I. S. Zagon \& P. J. McLaughlin (Eds.), Receptors and the developing nervous system (pp. 21-42). London, United Kingdom: Chapman and Hall.

Costa, L. G. (1995). Effect of developmental neurotoxicants on muscarinic receptors and intracellular signaling pathways. In C. A. Shaw (Ed.), 
Receptor dynamics in neural development (pp. 305320). Boca Raton, FL, United States: CRC Press.

Costa, L. G. (1998). Ontogeny of second messenger systems. In W. Slikker \& L. W. Chang (Eds.), Handbook of developmental neurotoxicology (pp. 275-284). San Diego, CA, United States: Academic Press.

Costa, L. G., Balduini, W., \& Reno, F. (1995). Muscarinic receptor stimulation of phospholipase D activity in the developing brain. Neuroscience Research Communications, 17, 169-176.

Costa, L. G., \& Guizzetti, M. (1999). Muscarinic cholinergic receptor signal transduction as a potential target for the developmental neurotoxicity of ethanol. Biochemical Pharmacology, 57, 721-726.

Costa, L. G., Guizzetti, M., Oberdoester, J., Yagle, K., Costa-Mallen, P., Tita, B., . . . Valeri, M. (2001). Modulation of DNA synthesis by muscarinic cholinergic receptors. Growth Factors, 18, 227-236.

Costa, L. G., Kaylor, G., \& Murphy, S. D. (1986). Interaction of choline with muscarinic receptorstimulated phosphoinositide metabolism in the rat brain. Naunyn-Schmiedeberg's Archives of Pharmacology, 334, 536-539.

Costa, L. G., \& Murphy, S. D. (1984). Interaction of choline with nicotinic and muscarinic cholinergic receptors in the rat brain in vitro. Clinical and Experimental Pharmacology and Physiology, 11, 649654.

Costa, L. G., Yagle, K., Vitalone, A., \& Guizzetti, M. (2004). Alcohol and glia in the developing brain. In M. Aschner \& L. G. Costa (Eds.), Role of glia in neurotoxicity (pp. 343-354). Boca Raton, FL, United States: CRC Press.

Coyle, J. T., \& Yamamura, H. I. (1976). Neurochemical aspects of the ontogeny of cholinergic neurons in the rat brain. Brain Research, 188, 429-440.

Crews, F. T., Miller, M. W., Ma, W., Nixon, K., Zawada, W. M., \& Zakhari, S. (2003). Neural stem cells and alcohol. Alcoholism: Clinical and Experimental Research, 27, 324-335.

Cui, S. J., Terwai, M., Schneider, T. A., \& Rubin, R. (1997). Ethanol promotes cell death by inhibition of the insulin-like growth factor-I receptor. Alcoholism: Clinical and Experimental Research, 21, 1121-1127.

Davies, D. L., \& Smith, D. E. (1981). A Golgi study of mouse hippocampal CA1 pyramidal neurons following perinatal ethanol exposure. Neuroscience Letters, 26, 49-54.

Dobbing, J., \& Sands, J. (1979). Comparative aspects of the brain growth spurt. Early Human Development, 3, 7983.

Giordano, G., Guizzetti, M., Dao, K., Mattison, H. A., \& Costa, L. G. (2011). Ethanol impairs muscarinic receptors-induced neuritogenesis in rat hippocampal slices: Role of astrocytes and extracellular matrix proteins. Biochemical Pharmacology, 82, 1792-1799.

Giordano, G., Li, L., White, C. C., Farin, F. M., Wilkerson, H. W., Kavanagh, T. J., \& Costa, L. G. (2009). Muscarinic receptors prevent oxidative stressmediated apoptosis induced by domoic acid in mouse cerebellar granule cells. Journal of Neurochemistry, 109, 525-538.

Guerri, C., Pascual, M., \& Renau-Piqueras, J. (2001). Glia and fetal alcohol syndrome. Neurotoxicology, 22, 6581.

Guizzetti, M., Bordi, F., Dieguez-Acuna, F. J., Vitalone, A., Madia, F., Woods, J. S., \& Costa, L. G. (2003). Nuclear factor $\mathrm{kB}$ activation by muscarinic receptors in astroglial cells: Effect of ethanol. Neuroscience, 120, 941-950.

Guizzetti, M., \& Costa, L. G. (1996). Inhibition of muscarinic receptor-stimulated glial cell proliferation by ethanol. Journal of Neurochemistry, 67, 22362245.

Guizzetti, M., \& Costa, L. G. (2000a). Muscarinic receptors, protein kinase $\mathrm{C}$ isozymes and proliferation of glial cells: Effects of ethanol. Neurotoxicology, 21, 1117-1122.

Guizzetti, M., \& Costa, L. G. (2000b). Possible role of protein kinase $\mathrm{C}$ in muscarinic receptor-induced proliferation of astrocytoma cells. Biochemical Pharmacology, 60, 1457-1466.

Guizzetti, M., \& Costa, L. G. (2001). Activation of phosphatidylinositol 3-kinase by muscarinic receptors in astrocytoma cells. Neuroreport, 12, 1639-1642.

Guizzetti, M., \& Costa, L. G. (2002). Effect of ethanol on protein kinase $\mathrm{C}$ and p70 S6 kinase activation by carbachol: A possible mechanism for ethanol-induced inhibition of glial cell proliferation. Journal of Neurochemistry, 82, 38-46.

Guizzetti, M., Costa, P., Peters, J., \& Costa, L. G. (1996). Acetylcholine as a mitogen: Muscarinic receptormediated proliferation of rat astrocytes and human astrocytoma cells. European Journal of Pharmacology, 297, 265-273.

Guizzetti, M., Moeller, T., \& Costa, L. G. (2003). Ethanol inhibits muscarinic receptor-mediated DNA synthesis and signal transduction in human fetal astrocytes. Neuroscience Letters, 344, 68-70.

Guizzetti, M., Moore, N. H., Giordano, G., \& Costa, L. G. (2008). Modulation of neuritogenesis by astrocyte muscarinic receptors. Journal of Biological Chemistry, 283, 31884-31897.

Guizzetti, M., Moore, N. H., Giordano, G., VanDeMark, K. L., \& Costa, L. G. (2010). Ethanol inhibits neuritogenesis induced by astrocyte muscarinic receptors. Glia, 58, 1395-1406.

Guizzetti, M., Moore, N. H., VanDeMark, K. L., Giordano, G., \& Costa, L. G. (2011). Muscarinic receptoractivated signal transduction pathways involved in the neuritogenic effect of astrocytes in hippocampal neurons. European Journal of Pharmacology, 659, 102-107.

Guizzetti, M., Thompson, B. D., Kim, Y., VanDeMark, K., \& Costa, L. G. (2004). Role of phospholipase D signaling in ethanol-induced inhibition of carbacholstimulated DNA synthesis of $1321 \mathrm{~N} 1$ astrocytoma cells. Journal of Neurochemistry, 90, 646-653.

Guizzetti, M., Wei, M., \& Costa, L. G. (1998). The role of protein kinase $\mathrm{C} \alpha$ and $\varepsilon$ isozymes in DNA synthesis induced by muscarinic receptors in a glial cell line. European Journal of Pharmacology, 359, 223-233. 
Heacock, A. M., Fisher, S. K., \& Agranoff, B. W. (1987). Enhanced coupling of neonatal muscarinic receptors in rat brain to phosphoinositide turnover. Journal of Neurochemistry, 48, 1904-1911.

Hobbs, C. A., Cleves, S., Melnyk, S., Zhao, W., \& James, S. J. (2005). Congenital heart defects and abnormal maternal biomarkers of methionine and homocysteine metabolism. American Journal of Clinical Nutrition, 81, 147-153.

Holler, T., Cermak, J. M., \& Blusztajn, J. K. (1996). Dietary choline supplementation in pregnant rats increases hippocampal phopholipase D activity of the offspring. The FASEB Journal, 10, 1653-1659.

Hosey, M. M. (1992). Diversity of structure, signaling, and regulation within the family of cholinergic muscarinic receptors. The FASEB Journal, 6, 845-852.

Ikonomidou, C., Bittigau, P., Ishimaru, M. J., Wozniak, D. F., Koch, C., Genz, K., . . . Olney, J. W. (2000). Ethanol-induced apoptotic neurodegeneration and fetal alcohol syndrome. Science, 287, 1056-1060.

Jones, K. L. (2011). The effects of alcohol on fetal development. Birth Defects Research (Pt. C), 93, 311.

Ladinsky, H., Consolo, S., Peri, G., \& Garattini, S. (1972). Acetylcholine, choline and choline acetyltransferase activity in the developing brain of normal and hypothyroid rats. Journal of Neurochemistry, 19, 1947-1952.

Larocca, J. N., Rodriguez-Gain, A. G., Rashbaum, W. K., Weidenheim, K. M., \& Lyman, W. D. (1994). Muscarinic receptor-dependent activation of phospholipase $\mathrm{C}$ in the developing human fetal central nervous system. Brain Research, 653, 9-15.

Lauder, J. M., \& Schambra, U. (1999). Morphogenetic roles of acetylcholine. Environmental Health Perspectives, 107 (Suppl. 1), 65-69.

Li, Q., Guo-Ross, S., Lewis, D. V., Turner, D., White, A. M., Wilson, W. A., \& Schwartzwelder, H. S. (2004). Dietary prenatal choline supplementation alters postnatal hippocampal structure and function. Journal of Neurophysiology, 91, 1545-1555.

Lipton, S. A., \& Kater, S. B. (1989). Neurotransmitter regulation of neuronal outgrowth, plasticity and survival. Trends in Neurosciences, 12, 265-270.

Miller, M. W. (1997). Effects of prenatal exposure to ethanol on callosal projection neurons in rat somatosensory cortex. Brain Research, 766, 121-128.

Miller, M. W., Astley, S. J., \& Clarren S. K. (1999). Number of axons in the corpus callosum of the mature macaca nemestrina: Increases caused by prenatal exposure to ethanol. Journal of Comparative Neurology, 412, 123-131.

Miller, M. W., \& Potempa, G. (1990). Numbers of neurons and glia in mature rat somatosensory cortex: Effects of prenatal exposure to ethanol. Journal of Comparative Neurology, 293, 92-102.

Miller, M. W., \& Robertson, S. (2003). Prenatal exposure to ethanol alters the postnatal development and transformation of radial glia to astrocytes in the cortex. Journal of Comparative Neurology, 337, 252266.
Montoya, D. A. C., White, A. M., Williams, C. L., Blusztajn, J. K., Meck, W. H., \& Schwartzwelder, H. S. (2000). Prenatal choline exposure alters hippocampal responsiveness to cholinergic stimulation in adulthood. Developmental Brain Research, 123, 25-32.

Moore, N. H., Costa, L. G., Shaffer, S. A., Goodlett, D. R., \& Guizzetti, M. (2009). Shotgun proteomics implicates extracellular matrix proteins and protease systems in neuronal development induced by astrocyte cholinergic stimulation. Journal of Neurochemistry, 108, 891-908.

Napoli, I., Blusztajn, J. K., \& Mellott, T. J. (2008). Prenatal choline supplementation in rats increases the expression of IGF2 and its receptor IGF2R and enhances IGF2-induced acetylcholine release in hippocampus and frontal cortex. Brain Research, 1237, 124-135.

Nguyen, L., Rigo, J. M., Rocher, V., Belachew, S., Malgrange, B., Rogister, B., . . . Moonen, G. (2001). Neurotransmitters as early signals for central nervous system development. Cell Tissue Research, 305, 187202.

Pagani, F., Zagato, L., Vergani, C., Cassari, G., Sidoli, A., \& Barale, F. E. (1991). Tissue-specific splicing pattern of fibronectin messenger RNA precursor during development and aging rat. The Journal of Cell Biology, 113, 1223-1229.

Perez-Torrero, E., Duran, E., Granados, L., GutierrezOspina, G., Cintra, L., \& Diaz-Cintra, S. (1997). Effect of acute prenatal ethanol exposure on Bergman glia early postnatal development. Brain Research, 746, 305-308.

Rauch, U., Feng, K., \& Zhou, X. H. (2001). Neurocan: A brain chondroitin sulfate proteoglycan. Cellular and Molecular Life Sciences, 58, 1842-1856.

Reno, F., Tan, X. X., Balduini, W., \& Costa, L. G. (1994). Administration of ethanol during the rat's brain growth spurt causes dose-dependent microencephaly and inhibition of muscarinic receptor-stimulated phosphoinositide metabolism. Research Communications in Substances of Abuse, 15, 141-150.

Riley, E. P., Infante, M. A., \& Warren, K. R. (2011). Fetal alcohol spectrum disorders: An overview. Neuropsychology Review, 21, 73-80.

Riley, E. P., Mattson, S. N., Sowell, E. R., Jernigan, T. L., Sobel, T. F., \& Jones, K. L. (1995). Abnormalities of the corpus callosum in children prenatally exposed to alcohol. Alcoholism: Clinical and Experimental Research, 19, 1198-1201.

Ryan, S. H., Williams, J. K., \& Thomas, J. D. (2008). Choline supplementation attenuates learning deficits associated with neonatal alcohol exposure in the rat: Effects of varying the timing of choline administration. Brain Research, 1237, 91-100.

Samson, H. H. (1986). Microcephaly and fetal alcohol syndrome: Human and animal studies. In J. R. West (Ed.), Alcohol and brain development (pp. 167-183). Oxford, United Kingdom: Oxford University Press.

Seth, P, \& Koul, N. (2008). Astrocyte, the star avatar: Redefined. Journal of Biosciences, 33, 405-421. 
Smith, D. E., \& Davies, D. L. (1990). Effect of perinatal administration of ethanol on the CA1 pyramidal cells of the hippocampus and Purkinje cells of the cerebellum: An ultrastructural survey. Journal of Neurocytology, 19, 708-719.

Streissguth, A. P., Landesman-Dwyer, S., Martin, J. C., \& Smith, D. W. (1980) Teratogenic effects of alcohol in human and laboratory animals. Science, 209, 353-361.

Tan, X. X., Castoldi, A. F., Manzo, L., \& Costa, L. G. (1993). Interaction of ethanol with muscarinic receptor-stimulated phosphoinositide metabolism during the brain growth spurt in the rat: Role of acetaldehyde. Neuroscience Letters, 156, 13-16.

Tan, X. X., \& Costa, L. G. (1995). Postnatal development of muscarinic receptor-stimulated phosphoinositide metabolism in mouse cerebral cortex: Sensitivity to ethanol. Developmental Brain Research, 86, 348-353.

Thomas, J. D., Abou, E. J., \& Dominguez, H. D. (2009). Prenatal choline supplementation mitigates the adverse effects of prenatal alcohol exposure on development in rats. Neurotoxicology and Teratology, 31, 303-311.

Thomas, J. D., Biane, J. S., O’Bryan, K. A., O’Neill, T. M., \& Dominguez, H. D. (2007). Choline supplementation following third-trimester-equivalent alcohol exposure attenuates behavioral alterations in rats. Behavioral Neuroscience, 121, 120-130.

Thomas, J. D., Garrison, M., \& O’Neill, T. M. (2004). Perinatal choline supplementation attenuates behavioral alterations associated with neonatal alcohol exposure in rats. Neurotoxicology and Teratology, 26, 35-45.

Thomas, J. D., Idrus, N. M., Monk, B. R., \& Dominguez, H. D. (2010). Prenatal choline supplementation mitigates behavioral alterations associated with prenatal exposure in rats. Birth Defects Research (Pt. A), 88, 827-837.

Thomas, J. D., La Fiette, M. H., Quinn, V. R. E., \& Riley, E. P. (2000). Neonatal choline supplementation ameliorates the effects of prenatal alcohol exposure on a discrimination learning task in rats. Neurotoxicology and Teratology, 22, 703-711.

Thomas, J. D., Monk, B., Idrus, N. M., Otero, N. K. H., \& Kelly, S. J. (2011). Mechanisms by which choline mitigates fetal alcohol disorders. Alcoholism: Clinical and Experimental Research, 35 (Suppl.), 274A.

Thomas, J. D., O’Neill, T. M., \& Dominguez, H. D. (2004). Perinatal choline supplementation does not mitigate motor coordination deficits associated with neonatal alcohol exposure in rats. Neurotoxicology and Teratology, 26, 223-229.

Tsuji, R., Fattori, V., Abe, S., Costa, L. G., \& Kobayashi, K. (2008). Effects of postnatal ethanol exposure at different developmental phases on neurotrophic factors and phosphorylated proteins on signal transductions in rat brain. Neurotoxicology and Teratology, 30, 228-236.

Tsuji, R., Guizzetti, M., \& Costa, L. G. (2003). In vivo ethanol decreases phosphorylated MAPK and p70S6 kinase in the developing rat brain. NeuroReport, 14, 1395-1399.
Ullian, E. M., Christopherson, K. S., \& Barres, B. A. (2004). Role for glia in synaptogenesis. Glia, 47, 209216.

VanDeMark, K. L., Guizzetti, M., Giordano, G., \& Costa, L. G. (2009a). The activation of M1 muscarinic receptor signaling induces neuronal differentiation in pyramidal hippocampal neurons. Journal of Pharmacology and Experimental Therapeutics, 329, 532-542.

VanDeMark, K. L., Guizzetti, M., Giordano, G., \& Costa, L. G. (2009b). Ethanol inhibits muscarinic receptorinduced axonal growth in rat hippocampal neurons. Alcoholism: Experimental and Clinical Research, 33, 1945-1955.

Volterra, A., \& Meldolesi, J. (2005). Astrocytes, from brain glue to communication elements: The revolution continues. Nature Neuroscience, 6, 626-640.

Wagner, A. F., \& Hunt, P. S. (2006). Impaired trace fear conditioning following neonatal ethanol: Reversal by choline. Behavoral Neuroscience, 120, 482-487.

Weiss, E. R., Maness, P., \& Lauder, J. M. (1998). Why do neurotransmitters act like growth factors? Perspectives on Developmental Neurobiology, 5, 323-335.

Wen, Z., \& Kim, H. Y. (2004). Alterations in hippocampal phospholipid profile by prenatal exposure to ethanol. Journal of Neurochemistry, 89, 1368-1377.

Wessler, I., Reinheimer, T., Klapproth, H., Schneider, F. J., Racke, K., \& Hammer, R. (1997). Mammalian glial cells in culture synthesize acetylcholine. Naunyn Schmiedeberg's Archives of Pharmacology, 356, 694697.

Wurtman, R. J., Cansev, M., Sakamoto, T., \& Ulus, I. H. (2009). Use of phosphatide precursors to promote synaptogenesis. Annual Review of Nutrition, 29, 5987.

Yagle, K., Lu. H., Guizzetti, M., Moeller, T., \& Costa, L. G. (2001). Activation of mitogen-activated protein kinase by muscarinic receptors in astroglial cells: Role in DNA synthesis and effect of ethanol. Glia, 35, 111120.

Yan, G. M., Lin, S. Z., Irwin, R. P., \& Paul, S. M. (1995). Activation of muscarinic cholinergic receptors blocks apoptosis of cultured cerebellar granule neurons. Molecular Pharmacology, 47, 248-257.

Yao, W. D., Rusch, J., Poo, M., \& Wu, C. F. (2000). Spontaneous acetylcholine secretion from developing growth cones of Drosophila central neurons in culture: Effects of camp-pathway mutations. Journal of Neuroscience, 20, 2626-2637.

Zeisel, S. H. (2011). What choline metabolism can tell us about the underlying mechanisms of fetal alcohol spectrum disorders. Molecular Neurobiology, 44, 185191.

Zhao, D., Berse, B., Holler, T., Cermak, J. M., \& Blusztajn, J. K. (1998). Developmental changes in phospholipase D activity and mRNA levels in rat brain. Developmental Brain Research, 109, 121-127.

Zou, J., Rabin, R. A., \& Pentney, R. J. (1993). Ethanol enhances neurite outgrowth in primary cultures of rat cerebellar macroneurons. Developmental Brain Research, 72, 75-84. 